\title{
O ENSINO DE FRANCÊS NO CONTEXTO DO PROGRAMA IDIOMAS SEM FRONTEIRAS: UM RELATO DE EXPERIÊNCIA
}

\author{
Sara Farias da Silva ${ }^{1}$ \\ Clarissa Laus Pereira Oliveira ${ }^{2}$ \\ Iane Inês Poyer ${ }^{3}$
}

\begin{abstract}
Resumo
Este artigo apresenta um relato de experiência no contexto da prática do Estágio Obrigatório Supervisionado I e II do curso de Licenciatura em Letras - Língua Francesa e Literaturas, da Universidade Federal de Santa Catarina. Foi a primeira vez que o Estágio supervisionado de francês, deste curso de Letras, se realizou no âmbito do programa Idiomas sem Fronteiras, desenvolvido pelo Governo Federal para oferecer aulas de língua francesa à comunidade universitária intencionada em participar de projetos de mobilidade internacional. Assim, o objetivo deste trabalho é discutir o aspecto didático de duas atividades desenvolvidas de acordo com a metodologia do Francês para Objetivo Universitário e ministradas para três turmas no decorrer do ano de 2019, com nível B1, com estudantes, em sua maioria, mestrandos e doutorandos da Universidade. Apresentaremos os resultados obtidos nessa prática com o intuito de contribuir com o campo da formação docente e com as discussões sobre ensino-aprendizagem de uma língua estrangeira no contexto do Francês para Objetivo Universitário.

Palavras-chave: Estágio Supervisionado de Francês. Idiomas sem Fronteiras. Francês para Objetivo Universitário.

\section{FRENCH TEACHING IN THE CONTEXT OF THE LANGUAGES WITHOUT BORDERS PROGRAM: AN INTERNSHIP EXPERIENCE REPORT}

\begin{abstract}
This article presents an experience report in the context of the practice of the Supervised Obligatory Internship I and II of the Bachelor Degree in Letters - French Language and Literature, from the Federal University of Santa Catarina. It was the first time that the supervised French internship in this Language course took place under the Languages without Borders program, developed by the Federal Government to offer French language classes to the university community intending to participate in international mobility projects. Thus, the

${ }^{1}$ Universidade Federal de Santa Catarina (UFSC), Florianópolis - Santa Catarina - Brasil. Doutora em Linguística pela UFSC. Professora de Metodologia e Estágio Supervisionado de Francês (MEN-UFSC). Pesquisadora convidada da Université de Montréal - Canadá. ORCID: http://orcid.org/0000-0002-9508-6059. Email: foliesara@gmail.com.

${ }^{2}$ Universidade Federal de Santa Catarina (UFSC), Florianópolis - Santa Catarina - Brasil. Doutora em Literatura Comparada pela Universidade Federal do Rio Grande do Sul (UFRGS) e Universitat de Barcelona (UB). Professora da Universidade Federal de Santa Catarina (UFSC), responsável pelas disciplinas Metodologia do FLE e Estágios Supervisionados Obrigatórios I e II no curso de Letras Francês. ORCID: http://orcid.org/00000002-6172-6871. E-mail: clarissa.oliveira@ufsc.br

${ }^{3}$ Universidade Federal de Santa Catarina (UFSC), Florianópolis - Santa Catarina - Brasil. Graduada em Letras Francês - Licenciatura pela Universidade Federal de Santa Catarina. Professora em projetos de extensão de português como língua de acolhimento, de italiano e de francês na UFSC. ORCID: http://orcid.org/0000-00029348-6673. E-mail: ianepoyer@yahoo.com.br
\end{abstract}




\section{Linguagens - Revista de Letras, Artes e Comunicação - ISSN 1981-9943 \\ Blumenau, v. 13, n. 2, p. 368-387, maio/ago. 2019 \\ DOI: http://dx.doi.org/10.7867/1981-9943.2019v13n2p368-387}

objective of this work is to discuss the didactic aspect of two activities developed according to the French for University Objective methodology and taught to three classes during the year 2019, with level B1, with students, mostly, master's and PhD students at the University. We will present the results obtained in this practice in order to contribute to the field of teacher education and to the discussions on teaching and learning a foreign language in the context of French for University Objective.

Keywords: French supervised internship. Languages without Borders. French for Academic Purpose.

\section{INTRODUÇÃO}

Propomos nesse artigo relatar criticamente a experiência de docência adquirida pela aluna-estagiária Iane Inês Poyer ao longo do Estágio Supervisionado obrigatório para a obtenção do diploma de Licenciatura em Letras - Língua Francesa e Literaturas, realizado em 2019, na Universidade Federal de Santa Catarina (UFSC), no contexto do programa Idiomas sem Fronteiras - Francês (IsF). Pretendemos compartilhar a experiência adquirida durante o estágio no IsF, além de alimentar a reflexão acerca da didática do ensino de Língua Estrangeira (LE) dentro da perspectiva do Francês para Objetivo Universitário ${ }^{4}$ (FOU), portanto, destinado a um público específico. Para tanto, apresentamos a contextualização do ambiente no qual aconteceram as aulas e o arcabouço teórico que sustentou a nossa prática, bem como alguns exemplos de sequências didáticas especialmente elaboradas e trabalhadas durante o estágio.

As aulas ocorreram na UFSC, em Florianópolis, com sessões de duas horas, duas vezes por semana. Elas foram realizadas no âmbito do projeto IsF - Francês, coordenado a nível nacional pela Profa. Dra. Heloisa Albuquerque-Costa (USP) e, na UFSC, no primeiro semestre, pela Profa. Dra. Clarissa Laus Pereira Oliveira, que também foi orientadora de estágio e supervisionou a preparação das aulas e o seu desenvolvimento. No segundo semestre, o programa foi coordenado pela Profa. Dra. Luciana Wrege Rassier e a disciplina de Estágio orientada pela Profa. Dra. Sara Farias da Silva.

Durante os três anos em que a UFSC ofertou turmas do programa IsF - Francês, os professores responsáveis pelas turmas foram bolsistas de extensão universitária e, pela primeira vez, em 2019, foram alunos-estagiários do curso de Licenciatura em Letras. A formação inicial desses professores foi realizada no âmbito da disciplina Estágio obrigatório, com orientação voltada para o contexto do Francês para Objetivo Universitário.

O Programa IsF, braço linguístico do Programa Ciências sem Fronteiras, foi criado em

\footnotetext{
${ }^{4}$ Em francês o termo utilizado para FOU é Français sur Objectif Universitaire.
} 


\section{Linguagens - Revista de Letras, Artes e Comunicação - ISSN 1981-9943 \\ Blumenau, v. 13, n. 2, p. 368-387, maio/ago. 2019 \\ DOI: http://dx.doi.org/10.7867/1981-9943.2019v13n2p368-387}

2012 com o objetivo de aperfeiçoar a proficiência linguística de estudantes de nível superior, possibilitando-lhes acesso à intercâmbios internacionais. Dentro do Programa IsF existiam datas pré-determinadas e simultâneas para a realização dos cursos em todo o Brasil. Esses cursos eram divididos em módulos específicos que variavam em função de temas e de datas. Para a realização do estágio, no primeiro semestre, a coordenação local do programa optou pelo módulo Preparação para o DELF $B 1^{5}$, com exigência de nível de língua $\mathrm{B} 1$, curso intensivo com carga horária de dezesseis horas, ofertado duas vezes no mesmo semestre. No segundo semestre, a escolha foi pelo módulo Projeto individual de mobilidade acadêmica em países de língua francesa: preparação e apresentação oral, também com a exigência de nível de língua B1, curso intensivo com carga horária de trinta e duas horas. Tivemos, assim, ao longo do ano, sessenta e quatro horas de curso.

Inscreveram-se neste curso alunos, professores e servidores da instituição. O número de inscrições foi de quarenta e três na primeira oferta e cinquenta na segunda e terceira ofertas. No entanto, o número máximo de participantes por turma era de 25 alunos. Apesar de as informações quanto ao critério de conhecimento da língua estarem disponíveis no site, alguns estudantes se inscreveram no nível inadequado, fazendo com que outros candidatos com nível correspondente ao exigido ficassem sem a vaga. Teria sido necessária a realização de um nivelamento on-line anterior à inscrição para que o aluno pudesse cursar a turma referente ao seu nível e às suas competências em língua francesa. No entanto, já no contexto das ações pedagógicas do Estágio supervisionado, no início do curso foram realizadas uma entrevista e uma avaliação escrita com aqueles alunos que não puderam comprovar, através de certificados, a proficiência linguística para cursar o módulo. Outros estudantes, que não tinham o certificado de proficiência exigido ou que não passaram por avaliação, desistiram do curso. Esse era um dos elementos organizacionais complicados de gerir, pois muitas vagas ficaram ociosas apesar de haver mais inscritos do que oferta, e de serem realizadas várias chamadas com o intuito de ocupá-las.

Do ponto de vista das bases teóricas, utilizamos conceitos abordados e discutidos em nossa (contínua) formação, como quando do Encontro Regional IsF, um curso de formação para professores do IsF, do qual participamos em abril de 2019, na cidade de Porto Alegre. Alguns desses conceitos são apresentados a seguir.

Gostaríamos de reforçar a importância da prática docente na formação inicial de um

${ }^{5}$ DELF (Diplôme d'Etudes en Langue Française) B1 é o terceiro nível do Quadro Europeu Comum de Referências para Línguas (Cadre Européen Commun de Référence pour les Langues - CECRL), trata-se de uma definição de diferentes níveis de línguas redigida pelo Conselho Europeu. Disponível em: https://delfdalf.ambafrance-ca.org/fr/le-cecrl. Acesso em: 14 set. 2020. 


\section{Linguagens - Revista de Letras, Artes e Comunicação - ISSN 1981-9943 \\ Blumenau, v. 13, n. 2, p. 368-387, maio/ago. 2019 \\ DOI: http://dx.doi.org/10.7867/1981-9943.2019v13n2p368-387}

professor, pois o fato de colocar em prática as bases teóricas estudadas durante o curso de Letras Licenciatura em Francês contribuiu enormemente para a formação do licenciando. Ao iniciarmos o estágio no IsF, quando muitas decisões pedagógicas e organizacionais precisaram ser tomadas, conseguimos perceber, entender e, muitas vezes, desvendar algumas sutilezas teóricas que a experiência pode nos proporcionar. Um dos objetivos do estágio supervisionado, segundo Maciel e Mendes (2012, p. 3), é justamente o de "articular a formação inicial com a prática profissional”, contribuindo, assim, para a formação desse sujeito que vai além de seus saberes acadêmicos, pois através da vivência da docência o estagiário começará a conquistar um desenvolvimento tanto pessoal quanto profissional. Para Pimenta (1999, p. 20), os saberes da experiência são "aqueles que os professores produzem no seu cotidiano docente, num processo permanente de reflexão sobre sua prática”. Durante este estágio, nossa dinâmica foi a da prática reflexiva, em um processo de auto formação e de reelaboração dos saberes iniciais diante da prática vivenciada para que os saberes do futuro professor se constituam, possibilitando a formação de "um profissional crítico-reflexivo, com capacidade de tomar decisões sobre seu ser, saber ser e saber fazer que caracterizam a consciência das suas práticas de ensinar/aprender" (MACIEL; MENDES, 2012, p. 5). O estágio supervisionado, etapa fundamental na formação do futuro professor, não se trata simplesmente da aplicação das teorias didático-pedagógicas aprendidas, vai além disso, pois funciona como um "espaço de investigação sobre a prática pedagógica, de articulação teóricoprática e de mobilização, construção e reconstrução de saberes relativos à docência" (MACIEL; MENDES, 2012, p. 7).

De acordo com Oliveira e Cunha (2006), por meio do estágio, o futuro professor pode exercer suas habilidades, ter a possibilidade de adquirir uma visão crítica de seu espaço de atuação e incorporar atitudes práticas. Stahl e Santos (2012) explicam que ser professor exige muito mais do que apenas conhecimentos específicos de sua área de atuação, pois um professor precisa relacionar uma mescla de conhecimentos para ter uma formação docente integral. Logo, o estágio realizado no projeto IsF, que apresentaremos abaixo, foi um modo eficiente de promover a aproximação entre o ambiente de formação do futuro professor e os contextos reais de aprendizagem (GHEDIN; ALMEIDA, 2008).

\section{IDENTIFICAÇÃO DO CONTEXTO DE ENSINO E APRENDIZAGEM}

Após um semestre de preparação teórica, de observação de aulas e de discussão sobre metodologias de aprendizagem, o estágio de docência do curso de Letras Licenciatura em 


\section{Linguagens - Revista de Letras, Artes e Comunicação - ISSN 1981-9943 \\ Blumenau, v. 13, n. 2, p. 368-387, maio/ago. 2019 \\ DOI: http://dx.doi.org/10.7867/1981-9943.2019v13n2p368-387}

Francês se organiza em preparação, exposição e discussão de todos os planos de aula antes de cada encontro no campo de estágio. Todas as aulas ministradas são acompanhadas pela professora orientadora. Após a observação, dentro da perspectiva de uma reflexão crítica da prática docente, professora orientadora e estagiários relatam suas aulas e promovem uma discussão sobre os pontos relevantes vivenciados. Este compartilhamento de informações sobre a elaboração dos planos de aula e sobre as práticas de ensino foram fundamentais para a compreensão do ser professor e, portanto, para o amadurecimento dos estagiários.

Como dissemos anteriormente, foi a primeira vez que um estágio obrigatório teve lugar no programa IsF, na Universidade Federal de Santa Catarina, em Florianópolis. Sendo assim, compreendemos a importância de um breve histórico dessa instituição considerada pelo Times Higher Education (THE) a $9^{\mathrm{a}}$ melhor Universidade da América Latina (LAURINDO, 2020) e a terceira melhor Instituição Federal Brasileira. A UFSC foi fundada em 1960 com o objetivo de promover o ensino, a pesquisa e a extensão. Trata-se de uma Universidade pública, gratuita e de qualidade, e possui campi em mais quatro municípios: Araranguá, Curitibanos, Joinville e Blumenau (UFSC, 2019a). A unidade discente do Campus Florianópolis é constituída por 36.387 alunos distribuídos entre graduação, pós-graduação, ensino médio, fundamental e básico (UFSC, 2018). A graduação do campus Florianópolis dispõe de sessenta e quatro cursos diferentes (UFSC, 2019a).

No que concerne o programa Idiomas sem Fronteiras, ele foi criado em 2012 por especialistas em línguas estrangeiras a pedido da Secretaria de Educação Superior do Ministério da Educação (MEC) com o intuito de auxiliar estudantes de nível superior a terem acesso aos programas de mobilidade internacional ofertados pelo Governo Federal, como bolsas de intercâmbio. O programa oferecia cursos em diversos idiomas (Quadro 1) e tornouse importante no auxílio do processo de internacionalização do Ensino Superior Brasileiro, além de promover residência docente para profissionais de ensino de línguas estrangeiras. $\mathrm{O}$ programa incluía cursos a distância, cursos presenciais e aplicação de exames de proficiência. Os cursos presenciais eram oferecidos em universidades cadastradas como Núcleos de Línguas (NucLi) do Programa (IDIOMAS SEM FRONTEIRAS, 2017).

Quadro 1. Cursos, vagas oferecidas e número de professores do IsF

\begin{tabular}{|l|r|r|}
\hline \multicolumn{1}{|c|}{ Curso/período } & Número vagas oferecidas & \multicolumn{1}{c|}{ Número de professores } \\
\hline Inglês de 2014 a 2018 & 337.317 & 1.140 \\
\hline Espanhol de 2016 a 2018 & 6.240 & 88 \\
\hline
\end{tabular}


Linguagens - Revista de Letras, Artes e Comunicação - ISSN 1981-9943

Blumenau, v. 13, n. 2, p. 368-387, maio/ago. 2019

DOI: http://dx.doi.org/10.7867/1981-9943.2019v13n2p368-387

\begin{tabular}{|l|r|r|}
\hline Francês de 2016 a 2018 & 5.400 & 72 \\
\hline Italiano de 2016 a 2018 & 2.810 & 24 \\
\hline Alemão de 2016 a 2018 & 2.388 & 40 \\
\hline Japonês de 2016 a 2018 & 2.110 & 100 \\
\hline Português de 2017 a 2018 & 8.254 & 32 \\
\hline
\end{tabular}

Fonte: Brasil (2018)

Segundo o jornal O Estadão, de julho de 2019, o programa IsF permitiu que mais de 818.000 estudantes e professores universitários aprendessem um segundo idioma. Tratava-se de um programa essencial para estudantes brasileiros, pois no Brasil o ensino de idiomas na escola primária é deficiente e isso acaba sendo transferido, tornando-se um problema para as universidades, especialmente para estudantes que desejam seguir a carreira de pesquisadores (PALHARES, 2019).

Em 2020, o Governo Brasileiro decidiu desvincular o IsF do Ministério da Educação e Cultura e o vinculou à Associação Nacional dos Dirigentes das Instituições Federais de Ensino Superior (ANDIFES) que, hoje, apresenta-se como Rede ANDIFES Nacional de Especialistas em Língua Estrangeira - IsF, com propostas de atuação no tripé ensinopesquisa-extensão e trabalha com as Instituições Federais de Ensino Superior (IFES) que aderirem à rede por meio de carta convite ou chamada específica.

Os objetivos do ANDIFES - IsF continuam na mesma linha dos do antigo IsF - MEC, ou seja, formação inicial e continuada de professores de idiomas para atuarem em processos de internacionalização; desenvolvimento de proficiência linguística de estudantes, docentes e corpo técnico-administrativo das IFES credenciadas e da rede pública de Educação Básica, além de estrangeiros (em língua portuguesa), contribuindo para o desenvolvimento de uma política linguística para o país. E também o trabalho em rede para o desenvolvimento de políticas linguísticas no Ensino Superior Brasileiro (ANDIFES - IsF, 2019).

Com relação aos projetos de mobilidade acadêmica com universidades francófonas, a UFSC possui convênios com quatro universidades canadenses, duas belgas e cinquenta e sete universidades francesas. Até 2019, existiam na universidade cinco programas de intercâmbio que contemplavam alunos de qualquer curso de graduação, alguns com bolsas e outros não (UFSC, 2019b). Eram eles:

- Brasil France Ingénieur Technologie (BRAFITEC): cursos de tecnologia, fornece bolsa de estudos e exige nível B1 de língua francesa.

- Brasil France Agriculture (BRAFAGRI): disponível para cursos de engenharia de 


\section{Linguagens - Revista de Letras, Artes e Comunicação - ISSN 1981-9943 \\ Blumenau, v. 13, n. 2, p. 368-387, maio/ago. 2019 \\ DOI: http://dx.doi.org/10.7867/1981-9943.2019v13n2p368-387}

alimentos, fornece bolsa de estudos e exige nível B1 de língua francesa.

- Emerging Leaders in the Americas Program (ELAP): programa disponível para todos os estudantes de graduação. Acontece em Universidades Canadenses, fornece bolsa de estudos e exige nível intermediário a avançado em língua francesa.

- University Studies Abroad Consortium (USAC): não fornece bolsa, mas paga passagens, inscrição e moradia. É necessário ter completado mais de $40 \%$ do curso de graduação em Letras Licenciatura em Línguas Estrangeiras e deve-se realizar uma prova de língua inglesa, a competência em língua francesa não é exigida.

- Programa Outgoing (SINTER): programa disponível para todos os estudantes de graduação, não fornece bolsa, mas paga mensalidade referente à disciplina em que o aluno se inscreveu e exige nível B1 de língua francesa (UFSC, 2019b).

Visto o perfil do programa IsF vigente em 2019, foi necessário aprofundarmos nossos estudos no contexto singular do Francês para Objetivos Universitários. Uma vez que o público-alvo do programa tinha um objetivo muito específico, que era o de aproximar-se de universidades francófonas, foi preciso buscar um embasamento teórico que fundamentasse nossa prática.

\section{EMBASAMENTO TEÓRICO}

Nesta seção descrevemos o funcionamento do programa Idiomas sem Fronteiras e apresentaremos os embasamentos teóricos que nos orientaram para a realização do estágio, consequentemente, da nossa formação de futura professora de Francês Língua Estrangeira no contexto do Francês para Objetivo Universitário. Nas seções abaixo, especificaremos a razão pela qual a perspectiva pedagógica do projeto foi a do FOU, e como trabalhamos com o Quadro Comum Europeu de Referência para Línguas.

\subsection{IDIOMAS SEM FRONTEIRAS E FRANCÊS PARA OBJETIVOS UNIVERSITÁRIOS}

Desde a criação dos programas de internacionalização das universidades, constatou-se um significativo aumento da procura de cursos de línguas estrangeiras para preparar para a mobilidade internacional. As universidades, na sua maioria, oferecem cursos de línguas, porém, nesses cursos, os alunos têm uma progressão lenta, pois precisam de, no mínimo, dois anos para atingir o nível B1. Por isso, para acelerar esse processo, o programa IsF ofereceu cursos intensivos e específicos com foco no estudante que passaria pela experiência de 


\section{Linguagens - Revista de Letras, Artes e Comunicação - ISSN 1981-9943 \\ Blumenau, v. 13, n. 2, p. 368-387, maio/ago. 2019 \\ DOI: http://dx.doi.org/10.7867/1981-9943.2019v13n2p368-387}

intercâmbio. As aulas eram contextualizadas no meio acadêmico e no quotidiano dos futuros estudantes intercambistas, visando a prever as necessidades que estes teriam quando de sua estadia em outro país, preparando-os também para o contexto de sala de aula estrangeira, desde os comportamentos esperados da parte dos alunos até uma formação linguística sólida que os permitisse assistir às aulas e produzir trabalhos sem muitas dificuldades.

A diferença fundamental entre um curso de línguas durante o qual ensina-se uma língua para a comunicação em geral e um curso do IsF, segundo Albuquerque e Medeiros (2019), consistia no fato da progressão no IsF não ser linear, indo do simples ao complexo, como vemos na maioria dos livros didáticos. No IsF, as competências eram desenvolvidas de acordo com as necessidades dos alunos. Desse modo, o professor era levado a desenvolver sua autonomia para a elaboração de unidades didáticas inéditas. Para tanto, o perfil de um professor que desejava trabalhar em um programa do IsF precisava ser o de uma pessoa com iniciativa e que compreendesse seu papel de professor-pesquisador (ALBUQUERQUE, 2019).

Nesse sentido, como o programa IsF demandava um curso de francês voltado para um determinado objetivo, a metodologia do Francês para Objetivo Universitário se encaixava perfeitamente. A nomenclatura FOU surgiu a partir de discussões que visavam a conceber programas de formação em língua francesa específicos para cada contexto. Em um primeiro momento, falou-se de FOS, Francês para Objetivo Específico, que justamente nasceu

du souci d'adapter l'enseignement du Français Langue Étrangère (FLE) à des publics adultes souhaitant acquérir ou perfectionner des compétences en français pour une activité professionnelle ou des études supérieures ${ }^{6}$ (CUQ, 2003, p. 109).

No FOS o objetivo principal do ensino do francês é o de atender às necessidades específicas dos estudantes, utilizando metodologias e atividades direcionadas para a apropriação linguística no desempenho de determinadas atividades. A diferença que existe entre o francês geral e o FOS se encontra no nível lexical e também nas situações de comunicação que são voltadas para um meio específico, seja de trabalho ou de estudo, por exemplo.

A partir dessa perspectiva, surge um outro conceito uma declinação do FOS. Trata-se do FOU, Francês para Objetivo Universitário, que seria: “une spécialisation au sein du FOS visant à préparer des étudiants à suivre des études supérieures dont la langue d'enseignement

\footnotetext{
${ }^{6}$ Tradução nossa: da preocupação de adaptar o ensino de francês como língua estrangeira (FLE) a públicos adultos interessados em adquirir ou melhorar habilidades em francês para uma atividade profissional ou estudos superiores.
} 


\section{Linguagens - Revista de Letras, Artes e Comunicação - ISSN 1981-9943 \\ Blumenau, v. 13, n. 2, p. 368-387, maio/ago. 2019 \\ DOI: http://dx.doi.org/10.7867/1981-9943.2019v13n2p368-387}

est le français ${ }^{7}$, (BOUKHANNOUCHE, 2012, p. 1).

No FOU, assim como no FOS, os estudantes pertencem a diferentes áreas de conhecimento, como o Direito, a Medicina, a Química, entre outras. No entanto, o trabalho não é direcionado para uma área específica, mas para os tipos de competências necessárias para qualquer estudante que queira acessar um sistema universitário francófono. A intenção é a de tornar os estudantes capazes de compreender as aulas, saber tomar notas, fazer perguntas, fazer provas, redigir desde cartas de reclamação e motivação até textos mais complexos, conseguir ler livros especializados. Eles ainda são orientados para realizar determinadas tarefas, como preparar e apresentar uma comunicação, falar em público, e fazer resumos. Além disso, eles precisam compreender a organização da universidade para onde vão e os procedimentos administrativos necessários para sua admissão.

Não se pode deixar de lado o componente cultural, pois língua e cultura são indissociáveis e é necessário que se enalteça nos estudantes as diferenças e semelhanças culturais, além dos conhecimentos específicos sobre a cultura do país onde vão viver, o que é fundamental na integração dos estrangeiros em seu novo contexto social. Tudo isso precisa ser bem planejado pelo professor para maximizar o tempo, pois estes estudantes, na maioria das vezes não dispõem de muito tempo para aprender ou melhorar seu nível de língua (BOUKHANNOUCHE, 2012).

Segundo Mangiante e Parpette (2011), a metodologia FOU

consiste à construire les programmes de formation linguistique au plus près des situations ciblées. Elle suppose une connaissance précise de ces situations, des discours qui y circulent et des savoir-faire langagiers qu'il faut y maîtriser. Pour le public en formation, les enjeux sont souvent lourds et les délais courts ${ }^{8}$ (MANGIANTE; PARPETTE, 2011, p. 116).

Percebe-se que a formação linguística desses estudantes não pode, então, se restringir aos cursos de línguas habituais e de longa duração, pois esses alunos precisam desenvolver competências de comunicação tanto para um contexto mais amplo quanto para um contexto específico (o meio universitário) e dispõem de pouco tempo. Para tanto, no contexto FOU o professor precisa levar em conta uma diversidade de questões que vão desde os materiais que estão à sua disposição para a realização de seu trabalho até a possibilidade de investigar quais

\footnotetext{
${ }^{7}$ Tradução nossa: Uma especialização dentro do FOS destinada a preparar os alunos para o ensino superior cuja língua de ensino é o francês.

${ }^{8}$ Tradução nossa: consiste em criar programas de formação linguística o mais próximo possível das situaçõesalvo. Pressupõe um conhecimento preciso dessas situações, dos discursos que circulam nelas e do saber linguístico que deve ser dominado. Para o público em formação, os desafios são geralmente grandes e os prazos curtos.
} 


\section{Linguagens - Revista de Letras, Artes e Comunicação - ISSN 1981-9943 \\ Blumenau, v. 13, n. 2, p. 368-387, maio/ago. 2019 \\ DOI: http://dx.doi.org/10.7867/1981-9943.2019v13n2p368-387}

seriam as reais necessidades específicas da maioria dos estudantes da sua universidade, entre outros fatores (PARPETTE, 2014). Segundo diversos estudos, o que é primordial no momento da elaboração de programas FOU é a identificação das necessidades do público e dos objetivos de aprendizagem (MANGIANTE; PARPETTE, 2004; CARRAS et al., 2007; MOURLHON-DALLIES, 2008; ALBUQUERQUE, 2015).

A partir da criação do IsF, o FOU começa a ser utilizado cada vez mais no Brasil devido ao aumento de convênios com universidades estrangeiras francófonas que surgiram graças a uma vontade política do governo brasileiro da época de internacionalização do ensino superior. O Plano Nacional de Educação (PNE) visa a favorecer a criação e o aprimoramento de redes de cooperação universitária, bem como a criação de programas que facilitem a mobilidade estudantil, promovendo, assim, intercâmbios científicos e tecnológicos (PNE, 2014).

Dentro do IsF, uma equipe de professores trabalhou intensamente para desenvolver os programas dos cursos ofertados (ementas, objetivos, carga horária, justificativa, conteúdo programático, metodologia). Esses programas eram disponibilizados na plataforma do IsF para todas as universidades participantes. A partir dessas informações, foi necessário refletir sobre qual seria a melhor abordagem metodológica a ser utilizada para se trabalhar no contexto IsF-FOU. As avaliações de proficiência linguística certificadas pelo Ministério da Educação da França, desde o ano 2000, estão baseadas nos critérios estabelecidos pelo o Quadro Europeu Comum de Referência para as Línguas (QECR). Neste documento, que orienta os materiais didáticos e as práticas pedagógicas, a abordagem privilegiada é

très généralement [..., de type actionnel en ce qu'elle considère avant tout l'usager et l'apprenant d'une langue comme des acteurs sociaux ayant à accomplir des tâches (qui ne sont pas seulement langagières) dans des circonstances et un environnement donnés, à l'intérieur d'un domaine d'action particulier ${ }^{9}$ (CONSEIL DE L'EUROPE, 2001, p. 15).

Isso caracteriza uma abordagem intercultural que vê o aprendiz como um ator social. O capítulo 2 do QECR é dedicado à Perspectiva Acional (PA) (QECR, 2001, p. 15) e, nesse tipo de abordagem, Christian Puren (2002) esclarece que os estudantes são coautores de sua aprendizagem e, sendo assim, o professor deve considerar o aluno como tal, utilizando para isso a língua e a cultura como instrumentos de ação e não somente de comunicação. A partir

\footnotetext{
${ }^{9}$ Tradução nossa: geralmente [...] do tipo acional, na medida em que considera acima de tudo o usuário e o aprendiz de uma língua como atores sociais que precisam realizar tarefas (que não são apenas linguísticas) em circunstâncias e em ambientes determinados, dentro de um campo de ação específico.
} 


\title{
Linguagens - Revista de Letras, Artes e Comunicação - ISSN 1981-9943 \\ Blumenau, v. 13, n. 2, p. 368-387, maio/ago. 2019 \\ DOI: http://dx.doi.org/10.7867/1981-9943.2019v13n2p368-387
}

desta perspectiva de ensino-aprendizagem, não comunicamos somente para falar com o outro, mas para agir com o outro. Em sala de aula, os estudantes colaboram entre si, se ajudam para melhor progredir coletivamente em suas aprendizagens. Desse modo, não vemos mais o léxico e a gramática como objetivos linguísticos, mas como ferramentas linguísticas que poderão ser utilizadas pelos alunos para agir no mundo. Quando o professor pede ao aluno que fale com o outro, não se trata simplesmente de ato de palavra, mas de um ato social (PUREN, 2002).

\begin{abstract}
Cette perspective représente un tournant dans l'enseignement et l'apprentissage des langues en ce sens qu'elle redéfinit le statut de l'apprenant et des tâches qu'il a à accomplir. Ainsi l'apprenant n'est plus seulement tourné vers l'institution scolaire mais aussi vers la société. Par là même, les tâches qu'il est amené à réaliser sont à la fois scolaires et sociales ${ }^{10}$ (BAGNOLI, P.; DOTTI, E.; PRADERI, R.; RUEL, V. 2010, p. 5).
\end{abstract}

Esse ponto confirma a preocupação em dar um sentido à aprendizagem. Bourguignon explica que sob essa perspectiva, o professor é levado a se dirigir ao estudante como um “aprendiz-usuário" de uma língua. Para tanto é necessário que a aprendizagem da língua se faça através do uso da mesma dentro de ações de um contexto social, dando assim sentido à aprendizagem (BOURGUIGNON, 2007, p. 2).

Considerando a PA e o FOU, entendemos que seria coerente utilizar a escala de competências do QECR no desenvolvimento dos módulos que trabalhamos no IsF, pois, justamente, os dois primeiros (Preparação para o DELF B1) visavam a preparar os estudantes para uma prova de proficiência na qual eram avaliados os pontos citados no QECR, que explicaremos a seguir. E o terceiro módulo (Projeto individual de mobilidade acadêmica em países de língua francesa: preparação e apresentação oral) visava a prepará-los para estudar em um país francófono. Ambos os módulos exigiam proficiência em língua de nível B1.

\subsection{QECR (QUADRO COMUM EUROPEU DE REFERÊNCIA PARA LÍNGUAS)}

Utilizamos a escala de competências do QECR através da qual procuramos desenvolver as habilidades necessárias para que o aluno pudesse se adequar ao nível de exigência da prova DELF B1, exame de proficiência comumente exigido para a maioria dos intercâmbios com países francófonos.

\footnotetext{
10 Tradução nossa: Essa perspectiva representa um ponto de transformação no processo de ensino e aprendizagem de idiomas, no sentido de redefinir o status do aluno e as tarefas que ele deve realizar. Assim, o aluno não é mais voltado apenas para a instituição educacional, mas também para a sociedade. Da mesma forma, as tarefas que ele é levado a executar são tanto escolares quanto sociais.
} 


\section{Linguagens - Revista de Letras, Artes e Comunicação - ISSN 1981-9943 \\ Blumenau, v. 13, n. 2, p. 368-387, maio/ago. 2019 \\ DOI: http://dx.doi.org/10.7867/1981-9943.2019v13n2p368-387}

Outro aspecto importante a ser ressaltado é o fato das grades de avaliação das provas do DELF B1 serem baseadas no QECR $^{11}$ e, quando as utilizamos, percebemos claramente que o foco não está nos detalhes de erros de ortografia e gramática, mas sim na capacidade que o aluno tem de se comunicar. Os itens comunicativos são mais valorizados que os itens puramente linguísticos. Isto significa que se o sujeito é capaz de agir no mundo com as habilidades linguísticas que possui, não será necessário que saiba tudo sobre a língua e a gramática para compreender e se fazer compreender.

Ao considerar esses aspectos, realizamos uma pesquisa, através de um questionário físico, durante a aula, com os estudantes matriculados nos módulos que ministramos em 2019, na UFSC, para identificar seu propósito em aprender a língua francesa. Como resposta, a maioria declarou desejar estudar francês com o objetivo de fazer um intercâmbio para um país de língua francesa, confirmando o objetivo primeiro do IsF. Com base nessas informações e levando em conta o programa previsto, as aulas foram preparadas com documentos autênticos que abordavam, além de aspectos culturais, questões sobre o cotidiano em um país de língua francesa, sobre a vida de um estudante universitário na França: como encontrar informações sobre inscrição na universidade, aluguel, seguro de saúde; como proceder, em caso de uma visita médica; como escrever uma carta de motivação ou reclamação; como apresentar um trabalho na universidade. Através desses documentos autênticos, pudemos trabalhar um vocabulário específico no contexto de trabalhos dirigidos, curso magistral, provas, avaliações, entre outros gêneros textuais comuns ao meio universitário. A partir disso, abordamos vários pontos gramaticais, como vocabulário para opinar, opor-se a algo, argumentar; usar corretamente tempos verbais e articuladores lógicos. Durante o curso, foi dada atenção especial à produção oral, considerada pelos próprios alunos como a habilidade mais difícil de se adquirir. Em termos de materiais, além de buscar ideias em livros didáticos, também utilizamos sites como TV5Monde, Bonjour de France, RFI Savoirs e alguns vídeos produzidos pelas próprias universidades. Da mesma forma, aplicativos como Kahoot e Popplet foram utilizados para auxiliar a assimilação de conteúdo.

$\mathrm{Na}$ sequência, apresentaremos algumas atividades realizadas em aula, acompanhadas de uma análise crítica.

\footnotetext{
${ }^{11}$ Grille évaluation Delf B1 Production écrite : http://www.delfdalf.fr/ media/grille-evaluation-productionecrite-delf-b1-tp-2.pdf. Grille evaluation Delf B1 Production oral: http://www.delfdalf.fr/ media/grilleevaluation-production-orale-delf-b1-tp.pdf.
} 


\section{Linguagens - Revista de Letras, Artes e Comunicação - ISSN 1981-9943 \\ Blumenau, v. 13, n. 2, p. 368-387, maio/ago. 2019 \\ DOI: http://dx.doi.org/10.7867/1981-9943.2019v13n2p368-387}

\section{RELATOS DAS PRÁTICAS DOCENTES REALIZADAS NESSE ESTÁGIO}

Os dois primeiros módulos IsF foram de dezesseis horas cada um e tinham como objetivo preparar os alunos para o teste DELF B1. Portanto, a primeira coisa que fizemos foi verificar a proficiência linguística dos alunos para ter um diagnóstico mais preciso da turma e, assim, poder trabalhar melhor com as especificidades de cada grupo. Para isso, os alunos foram convidados a escrever um breve texto em francês, de acordo com o solicitado: "Escreva um breve perfil no qual você se apresenta (nome, idade, local de nascimento), descreva sua formação educacional ou profissional e o que está fazendo atualmente. Depois, você explicará um pouco por que deseja aprender francês e quais são seus planos para o futuro."

Através deste texto que obrigava os alunos a escreverem em tempos do passado, do presente e do futuro, foi possível ter um bom diagnóstico do nível de língua em que se encontravam. Embora todos tivessem sido capazes de produzir o texto, havia diferenças importantes que foi preciso resolver. Para tanto, uma atividade de remediação e de revisão do conteúdo gramatical foi realizada da seguinte maneira: foram escolhidas sentenças, que apresentavam erros, escritas pelos próprios alunos. Divididos em grupos de três alunos, eles deveriam descobrir os erros nas frases. A correção da atividade, em grande grupo, foi realizada pelos próprios alunos que escreviam suas frases, corrigidas por eles mesmos, no quadro e justificavam suas correções; a turma podia ajudar se a correção ainda não estivesse completa. Além disso, em caso de dúvida, o professor completava ou explicava novamente as regras gramaticais necessárias para melhor compreensão do assunto. Depois disso, no final da atividade, o professor oferecia aos alunos alguns exercícios sobre os erros mais frequentes para garantir a fixação do conteúdo. Dessa forma tentamos resolver as lacunas de língua que os alunos ainda possuíam, permitindo que pudessem continuar sua aprendizagem partindo de um nível de proficiência mais homogêneo a todos os alunos da classe. Exemplos de frases trabalhadas: Je travaille a le café de l'Université. (L'article contracté), Je ne suis pas très timide aussi. (La négation), Je ne peux parler pas en public parce que je suis timide. (La place de la négation).

Motivados pela curiosidade de ver as frases que saíram de seus próprios textos, os alunos foram capazes de pensar, discutir entre si, ajudar-se mutuamente e conseguir encontrar juntos uma boa resposta para suas próprias perguntas. Esse tipo de exercício funciona bem porque, de acordo com Dehaene (2018), pesquisador em neurociências, quando os sinais de erro e surpresa se espalham em nosso cérebro, eles "viennent corriger nos modèles mentaux, 


\section{Linguagens - Revista de Letras, Artes e Comunicação - ISSN 1981-9943 \\ Blumenau, v. 13, n. 2, p. 368-387, maio/ago. 2019 \\ DOI: http://dx.doi.org/10.7867/1981-9943.2019v13n2p368-387}

éliminer les hypothèses inappropriées et stabiliser les plus justes"12 (DEHANE, 2018, p. 33). Assim, o cérebro registra a maneira correta com mais segurança e solidez. Como reforçam Germain e Netten (2014), a correção do erro é crucial, pois quando se chama a atenção do aluno para o erro, o mesmo se torna consciente, permitindo o desenvolvimento de uma gramática interna correta. "C'est pourquoi il est important, une fois l'erreur remarquée, de fournir à l'élève un modèle de la forme correcte et, surtout, de lui faire utiliser et réutiliser celle-ci dans de nouveaux contextes, jusqu'à ce que son utilisation devienne non consciente"13 (GERMAIN; NETTEN, 2014, p. 9). Portanto, trabalhar com os erros dos alunos também é uma boa maneira de melhorar o aprendizado deles, e isso foi reconhecido pelos próprios alunos que revelaram, em diversas oportunidades, terem apreciado e aprendido muito com esse tipo de exercício.

É importante prestar atenção ao fato de que, nesse tipo de trabalho, os alunos colaboram entre si, ajudando-se a progredir coletivamente. Assim, de acordo com Christian Puren (2002), não consideramos mais o léxico e a gramática como objetivos linguísticos, mas como ferramentas linguísticas que podem ser usadas pelos alunos para se comunicar e agir no mundo.

Para trabalhar a produção oral, procuramos apresentar assuntos polêmicos para incitar os alunos a dialogarem, a se expressarem, logo, um dos temas escolhidos foi Covoiturage (carona solidária). Além de ser um estilo de viagem bastante utilizado pelos jovens franceses, trata-se de um tema polêmico porque, por diferentes razões, nem todas as pessoas estão dispostas a utilizar esse tipo de meio de transporte. Sendo assim, neste primeiro momento, nossa prática pedagógica consistiu em interpelar os alunos para identificar o que eles já sabiam sobre o assunto, distribuir um texto sobre o tema para leitura individual e, finalmente, pedir que os alunos o lessem em voz alta. No final desta atividade, após termos trabalhado as dificuldades de pronúncia percebidas durante a leitura coletiva, solicitamos aos alunos que, em casa, lessem um dos parágrafos deste mesmo texto, o gravassem para poder ouvir a si mesmos primeiro e, depois, os enviassem ao professor para posterior feedback sobre a pronúncia.

Para darmos continuidade à atividade em sala, no segundo momento, em pequenos grupos, os alunos deveriam conversar sobre o assunto, se utilizavam esse tipo de serviço e por

\footnotetext{
12 Tradução nossa: vêm para corrigir nossos modelos mentais, eliminar hipóteses inadequadas e estabilizar as mais corretas.

13 Tradução nossa: Por isso é importante que desde que um erro seja percebido, se forneça ao aluno um modelo da forma correta e o mais importante é fazer com que ele a reutilize em diversos contextos até que sua utilização se torne inconsciente.
} 


\section{Linguagens - Revista de Letras, Artes e Comunicação - ISSN 1981-9943 \\ Blumenau, v. 13, n. 2, p. 368-387, maio/ago. 2019 \\ DOI: http://dx.doi.org/10.7867/1981-9943.2019v13n2p368-387}

quê. Finalmente, em um terceiro momento, a classe foi dividida em dois grandes grupos sendo que um grupo era a favor da carona solidária e outro contra. Para preparar seus argumentos, os alunos puderam procurar mais informações na internet, ver as opiniões de outras pessoas sobre o assunto.

Após o debate, passamos a trabalhar o conteúdo gramatical e convidamos os alunos a procurarem articuladores lógicos no texto lido. Conforme os alunos iam citando os articuladores textuais encontrados, os distribuímos em um quadro dentro de uma tabela de classificação por função. Porém, antes de sugerir uma classificação, perguntamos aos alunos se eles sabiam fazê-lo, para que eles mesmos percebessem que existem categorias de sentido para os diferentes articuladores lógicos. Finalmente, solicitamos aos alunos que escrevessem um texto argumentativo sobre a utilização da carona solidária. Devemos ressaltar a importância de trabalhar a argumentação com esses alunos que tem a intenção de fazer intercâmbio em universidades francófonas, pois em textos produzidos pelos alunos nos cursos universitários trabalha-se muito com a argumentação. Assim, na elaboração de dissertações, teses, artigos científicos e até apresentações orais é indispensável fazer uso da argumentação e é justamente dentro da metodologia FOU, que procura preparar esses alunos especificamente para o mundo universitário, que encontramos nossa base de trabalho.

Essa foi uma sequência pedagógica para uma aula de, no mínimo, duas horas, pois ela aborda praticamente todas as competências. Na primeira parte, quando se introduziu o assunto, foi possível discutir sobre os meios de transporte que os alunos utilizavam para ir para a universidade. Na parte da discussão em duplas, os alunos mais inseguros puderam pedir conselho à professora sobre as melhores maneiras de formular as frases que queriam utilizar, ou sobre o léxico mais adequado. Quando se realiza esse tipo de atividade de discussão em pequenos grupos, o professor tem a possibilidade de observar como os alunos estão construindo suas frases, auxiliando-os individualmente.

$\mathrm{Na}$ conclusão da parte oral, na qual os alunos estavam divididos em dois grandes grupos, eles puderam colaborar entre si na busca dos melhores argumentos para defender seus pontos de vista. Isso eleva a autonomia dos alunos, uma vez que eles mesmos buscam o conhecimento necessário para realizar a atividade. O ponto alto dessa sequência pedagógica foi o debate, durante o qual os alunos se aplicaram para tentar convencer os colegas de que suas opiniões eram as melhores, pois como afirma Christian Puren, o aluno está implicado socialmente na defesa de uma ideia na qual ele acredita.

Esse tipo de atividade de interação oral é importante, pois, segundo Germain e Netten (2005), durante esse processo o aluno tem tendência a se concentrar especialmente na 


\section{Linguagens - Revista de Letras, Artes e Comunicação - ISSN 1981-9943 \\ Blumenau, v. 13, n. 2, p. 368-387, maio/ago. 2019 \\ DOI: http://dx.doi.org/10.7867/1981-9943.2019v13n2p368-387}

mensagem que quer transmitir, o que contribui para deixar as estruturas da língua e as palavras do vocabulário utilizado cada vez mais automáticas (procedurais), desenvolvendo, assim, sua capacidade implícita em L2. É durante essas atividades que o professor pode propor correções apropriadas, disponibilizando, desse modo, aos alunos a possibilidade de elaborar, implicitamente, hipóteses adequadas sobre o funcionamento da língua que estão aprendendo, fazendo com que, pouco a pouco, os próprios alunos consigam se corrigir mutuamente (GERMAIN; NETTEN, 2005).

No que diz respeito à escrita do texto, foi um momento durante o qual os alunos se concentraram para escrever, precisaram organizar todos os argumentos a favor e contra $\mathrm{o}$ tema debatido e encontrar a melhor maneira de colocar suas ideias no papel de forma clara e concisa. Trata-se de um exercício que sempre traz enormes progressos ao aluno, principalmente se o professor trabalhar bem o feedback dessa atividade.

\section{CONSIDERAÇÕES FINAIS}

Como sabemos, o estágio supervisionado, além de privilegiar o espaço de investigação sobre a docência dentro do qual se reflete sobre a prática de ensino e sobre o papel do professor, também contribui para a construção de uma identidade profissional do futuro professor graças ao compartilhamento de experiências com o orientador e com os colegas de classe, desde o planejamento das aulas até a gestão pedagógica da turma e do conteúdo ministrado. Pode-se dizer, assim, que o estágio supervisionado possibilita ao futuro professor em formação a apropriação de conhecimentos bem como a produção de saberes.

Com relação ao fato desse estágio ter sido desenvolvido dentro do programa IsF, cabe ressaltar que foi um campo riquíssimo em aprendizagens para futuros licenciados, envolvendo um trabalho bem específico dentro da abordagem FOU. Dedicação e desafio são inerentes ao estágio e à prática docente, no entanto, nesse contexto eles foram ainda mais importantes tendo em vista que praticamente não existiam materiais didáticos nessa área e os mesmos tiveram de ser elaborados. Tratou-se de uma combinação perfeita já que o professor em formação também precisa aprender a didatizar materiais autênticos para uso pedagógico.

Outra grande vantagem de ser professor-estagiário no programa IsF era a do público ser bastante variado (diversas áreas de conhecimento) e sempre motivado para aprender a língua. Entretanto, mesmo os alunos estando motivados, era necessário tornar as aulas dinâmicas, sempre buscando dar um sentido ao que se propunha. Assim, partindo dos temas que mais interessavam aos alunos, procurou-se trabalhar com a utilização da língua em 


\section{Linguagens - Revista de Letras, Artes e Comunicação - ISSN 1981-9943 \\ Blumenau, v. 13, n. 2, p. 368-387, maio/ago. 2019 \\ DOI: http://dx.doi.org/10.7867/1981-9943.2019v13n2p368-387}

contextos específicos. A prioridade era o uso da língua, e o seu funcionamento só era abordado e explicitado quando necessário para melhorar o desempenho dos alunos. Raramente as explicações de gramática eram explícitas, ou seja, os estudantes eram levados a deduzir as regras da língua a partir do uso (gramática reflexiva).

Com essa experiência de docência, foi possível compreender também que o professor não é o detentor de todos os saberes. Ele é apenas um mediador, alguém que conduz os alunos a buscarem por si mesmos as respostas às perguntas que se fazem, navegando por mares linguísticos. O professor é um provocador que deve fazer perguntas para suscitar hipóteses da parte dos alunos, para levá-los a refletir sobre as coisas. Na verdade, o professor deve ser aquele que ensina seus alunos a aprenderem por si só, é aquele que desperta neles a curiosidade de conhecer. Antes de querer transmitir algum conhecimento a alguém é preciso que essa pessoa seja instigada a querer saber, a querer descobrir do que se trata e que ela possa ser conduzida a chegar às suas próprias conclusões. De outro modo, isso não terá efeito educativo algum, ela não assimilará efetivamente o conteúdo e, logo, pouco aprenderá. É preciso que exista a pergunta para que se possa buscar uma resposta. Sem ela não se pode descobrir muita coisa.

No que concerne o IsF mais especificamente, como se tratava de um curso intensivo, ele tinha a característica de promover a aprendizagem mais rapidamente, mas, além disso, como era focado nas necessidades mais urgentes do aluno que visava a um intercâmbio, logo, aprendia o essencial para seus objetivos e em um menor espaço de tempo.

Após ter cumprido os Estágios I e II neste contexto singular de ensino-aprendizagem do francês, ficou evidente que o trabalho de um professor de língua deve sempre ser direcionado ao desenvolvimento da capacidade de comunicação de seu aluno e não à retenção de fórmulas gramaticais sem conexão direta com o uso da língua. Deve-se despertar o interesse dos alunos utilizando atividades diferenciadas e mantendo o foco nas quatro competências de produção e de compreensão. Nesse sentido, o professor precisa fazer com que o aluno seja o protagonista de seu próprio processo de aprendizagem, instigando-o a buscar o crescimento de seu conhecimento, preparando-o para a vida sociocultural da atualidade.

Essa experiência de estágio aqui relatado proporcionou uma abertura maior para a profissão de professor de língua, dando maior segurança ao futuro profisssional. Auxiliou na constituição de sua própria identidade, tanto a partir das reflexões realizadas sobre as atividades quanto na relação com os colegas e com os alunos, pois é principalmente na relação com o outro que constituímos nossas identidades. Fez com que o futuro professor 


\section{Linguagens - Revista de Letras, Artes e Comunicação - ISSN 1981-9943 \\ Blumenau, v. 13, n. 2, p. 368-387, maio/ago. 2019 \\ DOI: http://dx.doi.org/10.7867/1981-9943.2019v13n2p368-387}

conseguisse perceber que não era preciso ser dependente dos livros didáticos e que ele podia desenvolver ótimos trabalhos partindo de sua própria criatividade.

Evidencia-se, portanto, a importância do estágio docente, bem como de sua realização dentro de um programa como o IsF que se enquadra em uma abordagem nos moldes do Francês para Objetivo Universitário, permitindo, assim, o pleno desenvolvimento desse futuro professor formado em um ambiente propício para discussões sobre ensino-aprendizagem de uma língua estrangeira em contexto diferenciado.

\section{REFERÊNCIAS}

ALBUQUERQUE-COSTA, H. Des cours de français sur objectifs spécifiques en milieu universitaire: du Français Instrumental (FI) au Français sur Objectif Universitaire (FOU) à l'École Polytechnique de l'Université de São Paulo (USP). Synergies Argentine, n. 3, p. 11 23, 2015. Disponível em: https://gerflint.fr/Base/Argentine3/albuqerque_costa.pdf. Acesso em: 25 jun. 2019.

ALBUQUERQUE-COSTA, H.; MEDEIROS, H. D. O programa Idiomas sem Fronteiras Francês na Universidade de São Paulo: ações de internacionalização para a mobilidade acadêmica. Olhares \& Trilhas, Uberlândia, vol. 21, n. 2, 2019. Disponível em: http://www.seer.ufu.br/index.php/olharesetrilhas/article/view/49784/26551. Acesso em: 20 out. 2019.

ANDIFES -IsF. Associação Nacional dos Dirigentes das Instituições Federais de Ensino Superior, 2019. Disponível em: http://www.andifes.org.br/institucional/redeisf/. Acesso em: 10 set. 2020.

BAGNOLI, P.; DOTTI, E.; PRADERI, R. e RUEL, V. La perspective actionnelle:

Didactique et pédagogie par l'action en Interlangue. Trabalho apresentado no Tercer foro de Lenguas ANEP, Montevideo, 2010, p. 1-16. Disponível em:

http://www.myenglishpages.fr/docs_a_telecharger/dida/perspective_actionnelle_bagnoli.pdf?f bclid=IwAR315iPASkXrSLvRo8M9DGdF4tCAI-ZefUAGcl-qUQGRp56oLx94 V51BMN0. Acesso em: 10 nov. 2019.

BOUKHANNOUCHE, L. Le français sur objectif universitaire. Amerika [En ligne], 7, 2012. Disponível em: https://journals.openedition.org/amerika/3437. Acesso em: 25 jun. 2019.

BOURGUIGNON, C. Apprendre et enseigner les langues dans une perspective actionnelle : le scénario d'apprentissage-action. Conférence donnée le 7 mars 2007 à 1'Assemblée Générale de la Régionale de l'APLV de Grenoble. Disponível em: https://www.aplv-languesmodernes.org/spip.php?article865. Acesso em: 25 jun. 2019.

BRASIL. Ministério da Educação. Idiomas sem fronteiras. Relatório Nacional do Programa Idiomas sem Fronteiras. Dados atualizados até nov. 2018. Disponível em: http://isf.mec.gov.br/pesquisas-e-relatorios/33-pesquisas-e-relatorios/199-relatorionacional. Acesso em: 14 abr. 2020. 
CARRAS, C. ; TOLAS, J. ; KOHLER, P. ; SZILAGYI, E. Le français sur Objectifs spécifiques et la classe de langue. Paris : CLE International, 2007.

CONSEIL DE L'EUROPE. Cadre Européen Commun de Référence pour les Langues.

Les éditions Didier, Paris, 2001. Disponível em: https://rm.coe.int/16802fc3a8. Acesso em: 25 jun. 2019.

CUQ, J-P. Dictionnaire de didactique du français langue étrangère et seconde. Paris: CLE international, 2003.

DEHAENE, S. Apprendre! Les talents du cerveau, le défi des machines. Paris: Odile Jacob, 2018.

GERMAIN, C.; NETTEN, J. Comment enseigner à communiquer oralement dans une L2/LE ? In: Aspects culturels, linguistiques et didactiques dans l'enseignementapprentissage du français à un public non francophone. AIEQ, Québec, 2014. Disponível em: https://www.anlformation.com/wp-

content/uploads/2019/04/GermainNettenComment_enseigner_a_communiquer_oralement.pdf .pdf. Acesso em: 25 nov. 2019.

GERMAIN, C.; NETTEN, J. Place et rôle de l'oral dans l'enseignement/apprentissage d'une L2, Babylonia, n. 2, p. 7-10, 2005. Disponível em:

http://babylonia.ch/fileadmin/user_upload/documents/2005-2/germainnetten.pdf. Acesso em: 25 nov. 2019.

GHEDIN, E.; ALMEIDA, W. A. de. O estágio como aprendizagem dos processos de pesquisa. In: ENDIPE - XIV ENCONTRO NACIONAL DE DIDÁTICA E PRÁTICA DE ENSINO, 2008, Porto Alegre. Trajetórias e processos de ensinar e aprender lugares, memórias e culturas, Anais eletrônicos, 2008.

IDIOMAS SEM FRONTEIRAS, 2017. Disponível em: http://isf.mec.gov.br/24-programa-isf. Acesso em: 08 maio 2019.

LAURINDO, J. UFSC sobre para nona posição em ranking das melhores universidades da América Latina. NSC Notícias, Florianópolis, maio 2020. Seção Educação. Disponível em: https://www.nsctotal.com.br/noticias/ufsc-sobe-para-a-nona-posicao-em-ranking-dasmelhores-universidades-da-america-latina. Acesso em: 07 maio 2020.

MACIEL, E. M.; MENDES, B. M. M. O estágio supervisionado na formação inicial: algumas considerações. In: ENCONTRO DE PESQUISA EM EDUCAÇÃO, 6., 2010, Teresina. Anais... Teresina: [s.n.], 2010.

MACIEL, E. M.; MENDES, B. M. M. O Estágio supervisionado como espaço de vivência da prática de ensino. In: ENCONTRO NACIONAL DE DIDÁTICA E PRÁTICAS DE ENSINO, ENDIPE, 16., 2012. Anais... Campinas: FE/UNICAMP, 2012.. Disponível em: http://endipe.pro.br/ebooks-2012/3267p.pdf. Acesso em: 30 out. 2019.

MANGIANTE, J-M.; PARPETTE, C. Le français sur objectif spécifique: de l'analyse des besoins à l'élaboration d'un cours. Paris: Hachette, 2004. 


\section{Linguagens - Revista de Letras, Artes e Comunicação - ISSN 1981-9943 \\ Blumenau, v. 13, n. 2, p. 368-387, maio/ago. 2019 \\ DOI: http://dx.doi.org/10.7867/1981-9943.2019v13n2p368-387}

MANGIANTE, J-M.; PARPETTE, C. Le Français sur Objectifs Universitaires: de la maîtrise linguistique aux compétences universitaires. 2011. pp. 115-134. Disponível em: https://gerflint.fr/Base/Monde8-T1/mangiante.pdf. Acesso em: 20 jun. 2019.

MOURLHON-DALLIES, F. Enseigner une langue à des fins professionnelles. Paris: Didier, 2008.

OLIVEIRA, E. da S. G. de; CUNHA, V. L. O estágio supervisionado na formação continuada docente a distância: desafios a vencer e construção de novas subjetividades. RED. Revista de Educación a Distancia, Murcia (España), v. 5, n. 14, p. 1-18, mar. 2006. Disponível em: www.um.es/ead /red/ 14/ oliveira.pdf. Acesso em: 29 out. 2019.

PALHARES, I. Idiomas sem Fronteiras será encerrado pelo MEC. O Estadão. São Paulo, 19 jul. 2019. Disponível em: https://educacao.estadao.com.br/noticias/geral,idiomas-semfronteiras-sera-encerrado-pelo-mec,70002927793. Acesso em: 10 dez. 2019.

PARPETTE, C. Contexte local et stratégie de programmation en Français sur Objectif Universitaire. In: Le français sur objectif universitaire, Zagreb, FF Press (2014) Disponível em: https://journals.openedition.org/amerika/3437. Acesso em: 28 jun. 2019.

PIMENTA, S. G. Formação de professores: identidade e saberes da docência. In: PIMENTA, S. G. (Org). Saberes pedagógicos e atividade docente. São Paulo: Cortez, 1999. p. 15-34.

PNE - Plano Nacional de Educação. Lei n ${ }^{\circ}$ 13.005/2014. Disponível em: http://portal.mec.gov.br/index.php?option=com_content\&view=article\&id=16478\&Itemid=1 107. Acesso em: 28 jun. 2019.

PUREN, C. Perspectives actionnelles et perspectives culturelles en didactique des languescultures : vers une perspective co-actionnelle co-culturelle. In: L'interculturelle. Langues Modernes, $n^{\circ} 3 / 2002$. Paris, APLV (Association française des Professeurs de Langues Vivantes), p. 55-71. Disponível em: http://www.aplvlanguesmodernes.org/spip.php?article844. Acesso em: 25 jun 2019.

STAHL, L. R.; SANTOS, C. F. dos. O estágio nos cursos de licenciatura: reflexões sobre as práticas docentes. In: SEMINÁRIO DE PESQUISA EM EDUCAÇÃO DA REGIÃO SUL, ANPED SUL, 9., 2012. Anais... 2012. Disponível em:

http://www.ucs.br/etc/conferencias/index.php/anpedsul/9anpedsul/paper/viewFile/1351/462 Acesso em: 29 out. 2019.

UFSC. UFSC em números, 2018. Disponível em:

http://dpgi.seplan.ufsc.br/files/2019/09/UFSC-EM-NUMEROS-2009-A-2018.pdf. Acesso em: 22 jun. 2019.

UFSC. Estrutura da UFSC, 2019a. Disponível em: http://estrutura.ufsc.br/guia-dos-cursos-dagraduacao/. Acesso em: 19 jun. 2019.

UFSC. SINTER, 2019b. Disponível em: http://sinter.ufsc.br/. Acesso em: 19 jun. 2019. 